\title{
Breast cancer screening adherence rates and barriers of implementation in ethnic, cultural and religious minorities: A systematic review
}

\author{
CRISTIANA SOFIA FERREIRA ${ }^{1 *}$, JOANA RODRIGUES ${ }^{1 *}$, STEFANIE MOREIRA $^{1 *}$, \\ FILIPA RIBEIRO $^{1,2}$ and ADHEMAR LONGATTO-FILHO ${ }^{1-5}$
}

\begin{abstract}
${ }^{1}$ School of Medicine, ${ }^{2}$ Surgical Sciences Research Domain, Life and Health Sciences Research Institute (ICVS), School of Medicine, University of Minho, Braga, Minho 4710-057; ${ }^{3}$ ICVS/3B's-PT Government Associate Laboratory, Braga/Guimarães 4710-057, Portugal; ${ }^{4}$ Molecular Oncology Research Center, Barretos Cancer Hospital, Barretos, SP 14784-400; ${ }^{5}$ Medical Laboratory of Medical Investigation (LIM) 14, Department of Pathology, Medical School, University of São Paulo, SP 01246-903, Brazil
\end{abstract}

Received July 7, 2020; Accepted March 1, 2021

DOI: $10.3892 / \mathrm{mco} .2021 .2301$

\begin{abstract}
Breast cancer is the most common cancer affecting women worldwide. Adherence to breast cancer screening guidelines is frequently lower in racial, ethnic and cultural minority populations and is affected by potential inequities or barriers to screening that these minorities face. Therefore, the aim of the present study was to collect information from different minority groups worldwide, assess adherence to breast cancer screening and evaluate barriers or limitations causing non-adherence, which should facilitate the development of effective interventions. A search was conducted through PubMed and Web of Science. Studies were considered as eligible if they met the following criteria: i) Female patients; ii) breast cancer screening program implemented in the country; iii) minority groups; iv) asymptomatic; v) report written in Portuguese or English; vi) study published from 2015 onwards. The Critical Appraisal Skills Programme checklist was used for qualitative studies and the Strengthening The Reporting of Observational Studies in Epidemiology checklist for cross-sectional studies. From the 348 initial articles, 86 were removed due to duplication and 19 were selected, analyzed and summarized, accordingly. Of the 19 studies included, $5.3 \%$ were classified as high quality, $52.6 \%$ as moderate to high and $42.1 \%$ as moderate. A total of 15 studies
\end{abstract}

Correspondence to: Dr Adhemar Longatto-Filho, Surgical Sciences Research Domain, Life and Health Sciences Research Institute (ICVS), School of Medicine, University of Minho, Campus de Gualtar, Braga, Minho 4710-057, Portugal

E-mail: longatto@med.uminho.pt

*Contributed equally

Key words: breast cancer, breast cancer screening, breast cancer screening adherence, minority, breast cancer screening barriers were cross-sectional and 4 were qualitative, collectively including 250,733 women. The rate of adherence to mammogram in different minorities was evaluated, obtaining a mean value of $49.7 \%$ in the last 2 years, and statistically significant barriers were selected and divided into sociodemographic; personal; ethnic, cultural and religious; and external factors. The characteristics of each population play a major role in the population's breast health practices. If the population, adherence rates, barriers and inequities are carefully studied, screening models may be customized and participation to breast cancer screening can be optimized, thereby reducing the high breast cancer-associated mortality.

\section{Introduction}

Breast cancer (BC) is the most common cancer among women worldwide, affecting 2.1 million women annually. An estimated 627,000 women succumbed to BC in 2018, accounting for $\sim 15 \%$ of all cancer deaths among women (1).

BC screening programs provide an important opportunity for early $\mathrm{BC}$ detection and contribute to improved survival and reduced $\mathrm{BC}$-associated mortality (2-5). Screening is the key element for early detection of $\mathrm{BC}$, and it is widely recommended by professional guidelines and supported by organized screening programs in several countries around the globe. There are several screening modalities, among which mammography (MAM) is the most widely accepted (6). It has been repeatedly reported that MAM screening is the most effective method for detecting early-stage disease and decreasing mortality (7-10). However, in certain areas and communities with limited access to technology such as MAM, Clinical Breast Examination (CBE) plays a critical role. $\mathrm{CBE}$ is the examination of a woman's breasts by a healthcare professional who is experienced in identifying different types of abnormalities and warning signs in the breast, and it is particularly important in rural areas and developing countries (11).

A minority group refers to a category of people who experience a relative disadvantage as compared to members of a 
dominant social group. It is typically based on differences in observable characteristics or practices, such as ethnicity, race and religion, among others $(12,13)$.

Adherence to BC screening guidelines is frequently lower in racial, ethnic and cultural minority populations and, therefore, late diagnosis, worse prognosis and increased mortality are commonly observed in these groups (14). This adherence is affected by potential inequities or barriers to screening that these minorities face; thus, it is crucial for physicians to have the necessary information and skills to be able to reach these women, increasing the commitment to screening and reducing BC mortality. Furthermore, public health-related decisions and interventions must take into account these disparities between racial, ethnic and cultural groups to adopt the most efficient measures for dealing with this issue $(15,16)$.

A number of studies have recently been published on this field about different minorities (12-16). The aim of the present systematic review was to collect information from different minority groups worldwide, assess adherence to BC screening and evaluate barriers or limitations responsible for non-adherence in order to pinpoint specific failures and their causes. The findings may enable the development of effective interventions aimed at the identified barriers to screening, with the purpose of increasing screening among these women and, subsequently, reducing mortality. Using a systematic review-based study, the factors adversely affecting BC screening adherence were critically examined, particularly among minorities, and the main contingencies related to the adherence rates to $\mathrm{BC}$ screening were investigated in ethnic, cultural and religious minorities in order to assess the barriers of implementation of BC screening.

\section{Materials and methods}

Search methods. The primary search was conducted using the PubMed and Web of Science databases. The key words and Boolean operators used were as follows: 'Breast cancer' screening AND (adherence OR uptake) AND (barriers OR inequities). In PubMed, a time filter for the last 5 years was applied. In Web of Science, the search was made by topic and a filter for the years 2015, 2016, 2017, 2018, 2019 and 2020 was applied. The last update of the search was conducted on March 16th, 2020.

Duplicate citations were removed using Mendeley and the remaining results were organized using a Microsoft Excel document with records of the exclusion rationale.

The search focused on papers published in English due to the impact on science literature; additionally, papers published in Portuguese were also selected in order to include the potential observations of Portuguese authors on this subject. The search was initiated in 2015 due to the high number of publications before that year without the modification of impact in $\mathrm{BC}$ prevention in poor areas and minorities, and also due to the better impact of articles published from 2015 onwards in terms of quality of the information and also in terms of the number of women with significant cultural and religious diversity enrolled in these studies.

Eligibility criteria. Three independent reviewers evaluated all citations for eligibility and any disagreements were resolved by consensus.
Articles were considered when they fulfilled the following inclusion criteria: i) Female patients; ii) BC screening program implemented in the country; iii) minority groups; iv) asymptomatic patients; v) study written in Portuguese or English; and vi) study published from 2015 onwards.

The exclusion criteria were as follows: i) Age <18 years; ii) emergency examination; iii) previous history of $\mathrm{BC}$ or mastectomy; iv) family history of $\mathrm{BC}$; v) target population with congenital or chronic conditions; vi) no assessment of barriers to screening; and vii) intervention-based programs.

Data extraction, synthesis and analysis. Three review authors extracted all relevant information from the included articles and organized it in a Microsoft Excel document in a standardized form in order to facilitate comparison between studies.

The following details were collected: Study ID (authors, year of publication, country and main objective), design (type of study, target population, selection process, inclusion and exclusion criteria), characteristics of the population (number of study participants, age range, data collection method), BC screening details (type of screening recommended) and relevant findings of the study (screening adherence rates, barriers considered and outcomes of the study).

Critical appraisal. Three review authors independently appraised the selected articles and any disagreements were resolved by consensus.

For this purpose, the Critical Appraisal Skills Program (CASP) checklist was used for qualitative studies and the Strengthening The Reporting of Observational Studies in Epidemiology (STROBE) checklist for cross-sectional studies.

Studies were classified according to their quality assessment percentage as follows: 'High quality', $>85 \%$; 'moderate to high', 75-85\%; 'moderate', 60-75\%; 'low to moderate', 50-60\%; and 'low', $<50 \%$.

\section{Results}

Study selection. The study selection process is described in the flowchart shown in Fig. 1. The PubMed search yielded 198 results and the Web of Science search yielded 150 results. Of those, 86 were duplicates, resulting in 262 records after duplicate removal.

Of the 262 studies, 243 were excluded: 78 were not related to breast screening, 65 had a different target population, 38 were intervention-based studies, 19 were related to a different pathology, 18 were systematic reviews, 16 did not assess adherence and 9 were guidelines. Finally, 19 full-text articles in total were deemed as eligible and were included in the present review.

Critical appraisal. The quality parameters of the study based on STROBE and CASP are comprehensively presented in Fig. 2A and B, respectively. Of the 19 studies included, 5.3\% were classified as high-quality, $52.6 \%$ as moderate-to-high, $42.1 \%$ as moderate, and none of the articles selected were rated as low-to-moderate or low-quality. Of the cross-sectional studies, $66.7 \%$ failed to describe 


\section{PRISMA 2009 Flow Diagram}
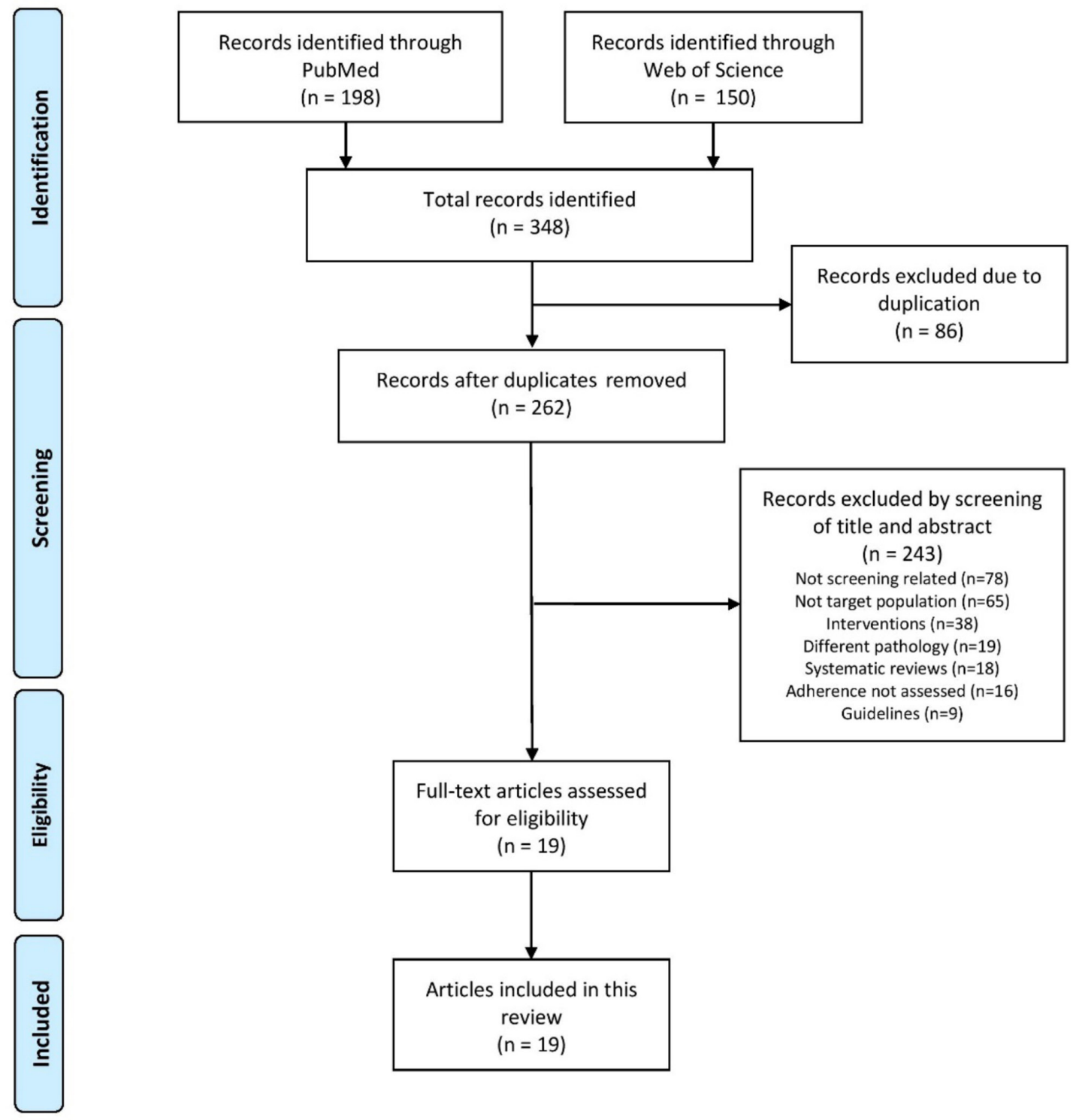

From: Moher D, Liberati A, Tetzlaff J, Altman DG, The PRISMA Group (2009). Preferred Reporting Items for Systematic Reviews and Meta-
Analyses: The PRISMA Statement. PLoS Med 6(7): e1000097. doi:10.1371/journal.pmed1000097

For more information, visit www.prisma-statement.org.

Figure 1. PRISMA flow diagram displaying the step-by-step selection process of the publications analysed in this review.

the efforts made to address potential sources of bias; only Miller et al (17) had included this parameter. Furthermore, $53.3 \%$ of cross-sectional studies did not describe how the study size was reached, while this was described in the studies of Adu et al (18), De Andrade Souza et al (19), Guo et al (20) and Vahabi et al (21). Finally, $46.7 \%$ of cross-sectional studies did not specify the source of funding or the role of the funders in the study. All the cross-sectional studies explained the scientific background and rationale for the investigation being reported in the introduction and summarized the key results in the discussion with reference to study objectives. All the qualitative studies had a high percentage on quality assessment; they all clearly stated the aims of the research and had an appropriate methodology.

Characterization of the studies. Of the 19 studies included in this review, 15 (79\%) were designed as cross-sectional and $4(21 \%)$ as qualitative (Table SI). The total number of participants of the articles analysed in this systematic review was 250,733 , mainly due to the article by Vahabi et al (21) 
A

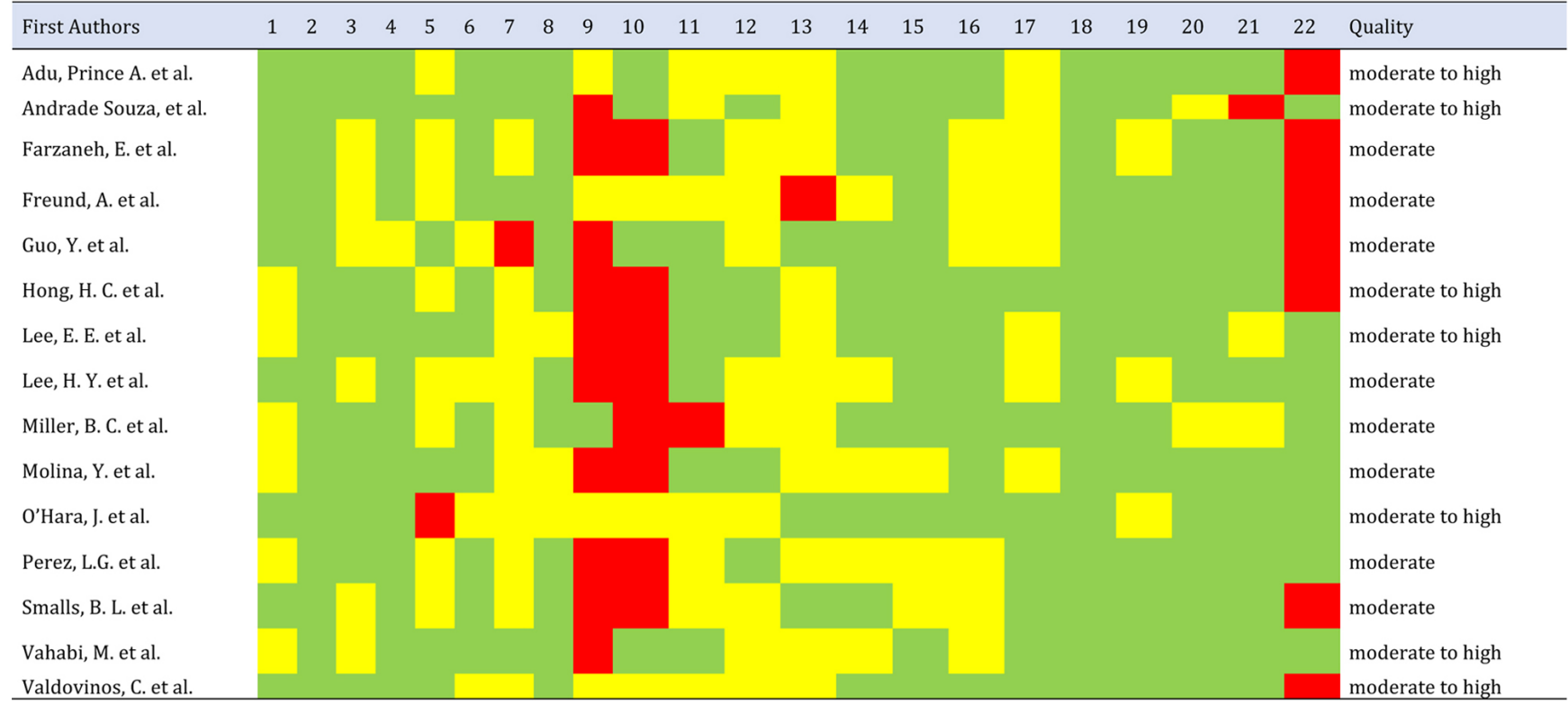

\section{B}

\begin{tabular}{|c|c|c|c|c|c|c|c|c|c|c|c|}
\hline First Authors & 1 & 2 & 3 & 4 & 5 & 6 & 7 & 8 & 9 & 10 & Quality \\
\hline Cohen, E. L. et al. & & & & & & & & & & & moderate to high \\
\hline Pilkington, L. et al. & & & & & & & & & & & high \\
\hline Shaw, T. et al. & & & & & & & & & & & moderrate to high \\
\hline Zorogastua, K. et al. & & & & & & & & & & & moderate to high \\
\hline
\end{tabular}

Figure 2. (A) STROBE and CASP-based quality criteria on publication, indicating strong values that vary from moderate to high standards of quality. Red, studies that do not comply with quality criteria; yellow, studies of moderate quality; and green, studies that comply with quality criteria. (B) Requirements for the quality assessment of four articles included in the current systematic review guided by CASP checklist revealed studies of high quality. STROBE, Strengthening The Reporting of Observational Studies in Epidemiology; CASP, Critical Appraisal Skills Program.

that included data from 238,218 women. The studies that included fewer participants (27 women) were the ones with the qualitative design, which is justified by this method limitation. The age range of the participants was similar in almost all articles (minimum, 40-50 years and maximum, $\sim 75$ years) and concordant with the screening programs recommended in each country. The exceptions were the articles that, in parallel, evaluated the screening for cervical cancer, for example Zorogastua et al (22), which included younger women. However, even these exceptions reported their results separately, considering only women aged $\geq 40$ years, for the BC screening analysis. The target populations of the 19 articles (Table SI) included in this systematic review were the following: English-, Arabic- and Italian-speaking women in Australia; immigrant women in Canada; Hispanic Community in the USA; Arab and ultra-orthodox Jewish women in Israel; immigrant women from Muslim majority and non-Muslim majority countries; Latin American women; African American women; African American and African-born Muslim women; Korean American women; Chinese American women; Azeri, Malay, Amazonian, Appalachian and Aboriginal women.

\section{Results}

In order to facilitate the interpretation of the results, the data were divided by main themes as follows:

Adherence rate. In the 19 studies analysed, a rate of adherence to MAM in the last 2 years was obtained, with percentages ranging from 10.1 to $80.2 \%$, with a mean $(\overline{\mathrm{x}})=49.7 \%$ and a median $(\mathrm{M})=52.5 \%$. By contrast, the rates of adherence to MAM at one point during the womens' lifetimes varied between 29.9 and $90 \%$, with $\bar{x}=63.5 \%$ and $M=71 \%$. Regarding adherence to $\mathrm{CBE}$ in the last 2 years, the rates ranged from 5.6 to $31.9 \%$, with $\bar{x}=18.7 \%$ and $M=18.6 \%$ (details are available in Table SI) (17-20,23-30).

Sociodemographic factors. Sociodemographic determinants were extensively mentioned in the articles analyzed. The most frequently mentioned obstacles were economic factors, education and age.

Economic factors were associated with screening uptake in 3 studies: Farzaneh et al (23) stated that high-income Azeri women living in Iran had a higher chance of ever having a MAM 
[odds ratio $(\mathrm{OR})=8.7,95 \%$ confidence interval $(\mathrm{CI}): 2.3-24.3$ ]; Vahabi et al (21) concluded that immigrant Muslim women in Canada who resided in low-income neighbourhoods had a lower chance of getting screened $(\mathrm{OR}=0.93,95 \% \mathrm{CI}$ : 0.92-0.91); finally, De Andrade Souza et al (19) reported that receiving government aid in the Amazonian community was associated with lower screening adherence $(\mathrm{OR}=2.27,95 \% \mathrm{CI}$ : 1.14-4.52).

Educational status was also widely evaluated, with conflicting results: Lee et al (31) stated that more years of education were associated with a lower adherence to screening, both MAM and CBE, in Korean Americans ( $\mathrm{OR}=0.77$ and 0.82, respectively); however, De Andrade Souza et al (19) concluded that Amazonian women who attended primary school (only) were almost 2 times more likely to not seek screening compared with women with a higher educational level (OR=1.98, 95\% CI: 1.58-2.05); Guo et al (20) also stated that African American women had 11\% more chance of getting screened if they had a higher educational level $(\mathrm{OR}=1.11, \mathrm{P}<0.05)$. This item was also mentioned by Pilkington et al (24) in a qualitative study as an important factor affecting screening behaviours among Aboriginal women.

Another important finding was the association between older age and a higher chance of screening, reported in 3 of the analysed articles: Korean immigrant women $(\mathrm{OR}=1.08)$, reported by Lee et al (31); African American women $(\mathrm{OR}=1.08)$, reported by Guo et al (20); and Korean American women $(\mathrm{OR}=1.12)$, reported by Lee et al (25).

Personal factors. Personal factors were extensively described in most of the articles. The most frequently mentioned obstacles to MAM and CBE were fear, distrust of health professionals or the healthcare system and knowledge of the procedures.

Fear was described in four articles. Arab women and ultra-orthodox Jewish women in particular, revealed having more fears regarding cancer-related losses (26), which was associated with more up-to-date $\mathrm{CBE}$ screening $(\mathrm{OR}=1.51$, 95\% CI: 1.19-3.00). In focus groups, African American and African-born Muslim women in NYC (22) stated negative perceptions and fear relating to $\mathrm{BC}$ screening as a barrier; Appalachian Kentucky women (32) mentioned specifically fear of detection, while Aboriginal women (24) reported fear of results.

Distrust of health professionals or healthcare system was also extensively reported. Korean immigrant women (31) reported distrust of health professionals, which was related to a lower chance of having a $\mathrm{CBE}(\mathrm{OR}=0.71)$. African American women (20) reported not trusting the physicians as a barrier to either MAM or CBE $(\mathrm{OR}=0.44)$. The results from Korean American women (27) in relation to MAM revealed that trusting the healthcare providers was associated with a better chance of having a screening done $(\mathrm{OR}=1.14,95 \% \mathrm{CI}$ : 1.01-1.29), while distrust in the healthcare system was associated with a lower chance of being screened (OR=0.84; 95\% CI: 0.72-0.99). In the study of Zorogastua et al (22), African American and African-born Muslim women in NYC mentioned medical mistrust as a barrier to screening in focus-based groups. In relation to healthcare, these women also reported only seeking medical attention when necessary and belief in alternative medicine as barriers to screening.
Knowledge of the procedure was also among the obstacles described. Korean immigrant women (31) declared better knowledge of the procedure as a facilitator in both MAM and $\mathrm{CBE}$ (OR=105.47 and 28.77, respectively). In focus-based groups, African American and African-born Muslim women in NYC (22) mentioned lack of knowledge/misconception as a barrier to screening, and Aboriginal women (24) also described lack of knowledge as a barrier. A total of $35 \%$ of US-based Latin American women (28) reported knowledge-based reasons for not adhering to $\mathrm{BC}$ screening.

Pain, embarrassment or discomfort are barriers often described in focus-based groups. Particularly, Appalachian Kentucky women mention pain and embarrassment associated with MAM screening (32) and Aboriginal women mention discomfort of the MAM screening (24), alongside shame and other factors.

Some populations also reported lack of time. African American women (20) reported lack of the time to visit doctors as a significant barrier to both MAM and $\mathrm{CBE}(\mathrm{OR}=0.46)$. African American and African-born Muslim women in NYC also mentioned lack of time as a barrier (22).

High self-efficacy is significantly described in two articles. Assessing Azeri women living in Ardabil, northwest Iran (23), showed that high self-efficacy was associated with a higher change of having a regular MAM $(\mathrm{OR}=2.56$, 95\% CI: 1.41-4.6). Similar results were observed in Korean immigrant women (25), with self-efficacy serving as a facilitator to MAM screening [adjusted OR $(A O R)=3.07$, 95\% CI: 1.48-6.38]. Modesty was described by Chinese American women (17) as being related to a lower chance of having a MAM $(\mathrm{OR}=4.78,95 \% \mathrm{CI}$ : 2.11-10.85). In addition, African American and African-born Muslim women in NYC mention modesty in focus-based groups as a barrier to screening (22). English-, Arabic- and Italian-speaking women living or working in Australia extensively described emotional barriers (OR=0.72, 95\% CI: 0.54-0.94) (33), whereas $19 \%$ of US-based Latin American women indicated psychological reasons for not adhering to BC screening (28).

The spousal role was found to be significant in first-generation of Korean American women married to Korean American men (25). Health beliefs and spousal support, particularly focused on importance of breast cancer prevention, were significantly associated with a higher chance of screening (AOR $=2.25,95 \% \mathrm{CI}: 1.40-3.63)$. The wife's perception of support received is also important for positive screening behaviours (AOR=1.99, 95\% CI: 1.14-3.48).

Perception of a higher risk of cancer is described as a motivator for screening among Arab and ultra-orthodox Jewish women (26), for both CBE and MAM (AOR=1.93, 95\% CI: $1.23-3.04$ and $\mathrm{AOR}=3.22$, 95\% CI: 1.53-6.61, respectively). Great confidence in screening efficacy is linked to regular MAM and regular CBE uptake (OR=4.2, 95\% CI: 1.9-9.3; and $\mathrm{OR}=1.25$, 95\% CI: 1.2-1.3, respectively) in Azeri women living in Ardabil, northwest Iran (23). Perceiving greater advantages of CBE appears to favour CBE screening in Arab and ultra-orthodox Jewish women (AOR $=1.82$, 95\% CI: 1.45-2.29) (26). Perceived lack of need $(\mathrm{OR}=0.27,95 \% \mathrm{CI}: 0.13-0.58)$ and perceived lack of access $(\mathrm{OR}=0.36,95 \% \mathrm{CI}:$ 0.16-0.82) appear to be significant barriers in non-adherent Chinese American women (17). A total of 
14\% of US-based Latin American women indicated no reason and $31 \%$ economic-based reasons for non-adherence (28).

Ethnic, cultural and religious factors. Factors associated with the participants culture and religion were mentioned in a few articles, most of which had a qualitative design. Shaw et al (29) revealed, through focus groups, that spiritual and religious beliefs (for example, Aurat, fatalism and black magic) play an important role in BC screening among Malay women in Singapore. Furthermore, the confidence in traditional medicine and the distrust in western practices among those women, as well as the role of family and community ties and shared beliefs, were also among the factors mentioned. In the qualitative study conducted by Zorogastua et al (22), focus groups with African Muslim women in the USA revealed 4 themes related to this topic: 'Role of religion', 'role of men', 'role of community' and 'stigma and shame'.

In the last qualitative study, Pilkington et al (24), through semi-structured interviews, focus group discussions and yarning circles, stated that perceived support was important to BC screening adherence among Aboriginal women in West Australia. Finally, Freund et al (26) reported that, having higher religious belief scores was associated with a lower MA uptake among Arab and ultra-orthodox Jewish women in Israel (OR=0.62, 95\% CI: 0.39-0.82).

External factors. Regarding factors external to the participants' characteristics or cultural context, a few statistically significant barriers were identified. The first, mentioned in at least 6 of the articles analysed, is access to healthcare: Vahabi et al (21) (Muslim women in Canada) and Guo et al (20) (African American women) assessed that not having a primary care physician reduced the odds of screening adherence $(\mathrm{OR}=0.20$ and 0.71 , respectively); Hong et al (27) stated that Korean American women with regular doctors or healthcare centres were nearly 30 times more likely to get screened $(\mathrm{OR}=29.91 ; 95 \% \mathrm{CI}$ : 3.75-238.13); similarly, Lee et al (25) concluded that Korean American women were more adherent to screening if they had regular access to healthcare $(\mathrm{OR}=2.44,95 \% \mathrm{CI}$ : 1.34-4.64); a self-perceived lack of access to healthcare among Chinese American women was associated with reduced chances of screening uptake (OR=0.36, 95\% CI: 0.16-0.82) in the study by Miller et al (17); finally, having had a medical consultation in the past year was associated with a lower chance of non-adherence in Amazonian women $(\mathrm{OR}=0.16,95 \% \mathrm{CI}$ : 0.05-0.46) in the study by De Andrade Souza et al (19). Second, 4 articles analysed the impact of having a positive reinforcement for screening: O'Hara et al (33) stated that receiving a screening invitation increased the odds of adherence among English-, Arabic- and Italian-speaking women in Australia $(\mathrm{OR}=3.46)$; having a physician's recommendation among Arab and ultra-orthodox Jewish women (26) was linked to an increased screening uptake (OR=1.82, 95\% CI: 1.45-2.29); De Andrade Souza et al (19) stated that having been visited by a healthcare agent lowered the odds of non-adherence to screening for Amazonian women $(\mathrm{OR}=0.43$, 95\% CI: 0.22-0.85); the qualitative study by Pilkington et al (24), after conducting semi-structured interviews, focus group discussions and yarning circles, suggested that a mobile van would increase the screening adherence in the Aboriginal women community. Third, the sex of the physician or healthcare provider was also linked to screening adherence: Vahabi et al (21) assessed that having a male doctor reduced the odds of Muslim immigrant women in Ontario seeking screening (OR=0.88, 95\% CI: 0.88-0.89), and Guo et al (20) associated having a female healthcare provider with an increased chance of adherence $(\mathrm{OR}=3.23)$ among African American women. Finally, the qualitative study by Cohen et al (32) stated, through semi-structured interviews, that impersonal and unprofessional MAM experiences adversely affected the screening behaviours of Appalachian Kentucky women.

\section{Discussion}

According to the American Cancer Society (34), MAM rates are expected to increase to $90 \%$ among American women in the next few years. In our studies, values have ranged from $43-75 \%$ at least once to $10.1-71.3 \%$ in the last 2 years and 26-80.2\% in the last year. According to the Cancer Care Ontario (35), the goal was to reach a $70 \%$ of MAM rate. The rates reported herein from the minorities in Canada were 56.1 and $51 \%$ in the last 2 years, which is considerably lower compared with the national target. The Breast Screen Singapore (36) reported that the programme aims to achieve a target of $70 \%$. In the present study, the adherence rate to MAM in the last 2 years was $44.4 \%$, which is lower compared with the set target. The Breast Screen Australia data from 2014-2015 (37) show an adherence rate of 53.7\%. In our cross-sectional study, a MAM adherence of $69 \%$ was obtained, which is considered satisfactory. According to the Israel Cancer Association, the compliance to MAM among Arab women was $49 \%$ in 2001, whereas it is currently similar to that of Jewish women at $70 \%$ (38). The results of the present study were quite contradictory, with Jewish ultra-Orthodox women having a screening rate of $50.6 \%$ and Arab women $72.7 \%$. In Brazil, the findings revealed low national MAM coverage, with $32 \%$ in the $50-59$ years age group and $25 \%$ in the $60-69$ years age group (39). Although no more recent data were included, the present study also demonstrated a low MAM coverage, with a rate of $44.4 \%$ in the last 2 years.

Similar to the present findings, previous studies reported an association between high income and higher BC screening rates $(40,41)$. Furthermore, our analysis is concordant with the literature that also shows an association between lower educational level and inadequate BC screening. However, Lee et al (31) reported that more years of education were associated with lower adherence to BC screening in Korean American women. This may be attributed to the fact that women with a higher level of education may be more concerned of radiation exposure during MAM, which may also act as a barrier $(42,43)$.

Older age has been associated with a higher chance of screening uptake among Korean immigrant (31), African American (20), and Korean American women (25). Surprisingly, no additional evidence was found in the literature to support this hypothesis. This is an important topic for future researches to consider in order to be able to intervene.

The results of the present study suggest that fear may act as both a motivator (when relating to cancer-related loss) and 
as a barrier (when related to fear of the screening process or diagnosis). The literature is contradictory, so a critical review was performed to find a consensus for anxiety, worry and fear as BC screening predictors (44). It was suggested that fear has diverse effects on screening behaviour, with a specific association of lower adherence with higher fear (45). Similar to our review, it was hypothesized that the fear of cancer may favour screening. Fear of negative outcomes appeared to occupy a middle ground in terms of impact on screening behaviour. Furthermore, a systematic review of qualitative studies found that a common barrier to $\mathrm{BC}$ screening was fear of a positive screening result and of pain associated with the procedure (45).

Distrust of healthcare professionals or system, according to our findings, was correlated with lower adherence in four studies, which mention three immigrant minorities in the USA: Korean, African American and African-born Muslim women. According to the literature, distrust of the healthcare system is known as a significant predictor of the last CBE and MAM (46). In a review about this topic, none of the studies analyzed reported a positive association between distrust and care (47)

In our findings, lack of knowledge or misconception about the procedure was an obstacle described by Korean immigrant, African American, African-born Muslim, Aboriginal and US-based Latin American women. Similarly, Chinese American women described perceived lack of need as a barrier. In the review of qualitative studies mentioned earlier, lack of knowledge about the screening procedure was one of the most important barriers (45).

Pain and embarrassment were also important barriers according to our findings, mentioned by Appalachian Kentucky and Aboriginal women in focus-based groups. In the review of qualitative studies, fear of pain was a common factor (45). Most women also mentioned embarrassment as a barrier, particularly when the healthcare professional was male. By contrast, another study concluded that the majority of women described MAM as painful, but relatively few indicated that the pain may deter them from future screening (48).

Highly religious women, as well as those who believe in black magic and other curative methods, were less likely to seek screening. These women often placed more trust in alternative medicine rather than in western practices $(29,49)$.

Another conviction that diminished adherence was faith in destiny. These findings are controversial in the literature, with some articles reporting that religious women are more likely to undergo screening $(50,51)$.

Therefore, it would be of value assessing each religion separately in order to be able to correctly address this issue in clinical practice.

As regards the role of family, men and cultural factors, the effects on BC screening uptake are also distinct. Family is important for encouraging women to undergo screening (52), while the cultural context can often function as a barrier to screening, due to the stigma associated with cancer diagnosis in some cultures (53). The role of men is quite pronounced and restraining in some cultures, with disapproval and forbidding of screening, particularly if the physician is male (54). In conclusion, it is important to study these issues among different contexts, preferably with qualitative methods, in order to improve clinical approach to non-adherent women.
The articles that explored access to healthcare were unanimous in the conclusion that women with higher self-perceived access, primary care physicians and regular medical consultations are more likely to seek BC screening (55). This statement is concordant with the literature. Having a regular primary care provider is known to promote screening and the potential explanation is that these professionals help with reminding and managing patients' clinical examinations (56-59).

The articles that evaluated the impact of bringing healthcare providers closer to women that need screening, for example with screening invitations, have all concluded that this type of dynamics improved the adherence to screening. These findings are similar to those found in the literature (60). The remarkable role of some religious institutions that provide means and education to women attending church, should also be mentioned (61).

The sex of the physician was also found to play an important role, with a higher adherence among patients who have a female doctor. The literature suggests that this may be associated with the differences in the beliefs of male and female primary care providers regarding screening (30).

There were certain appreciable limitations to the present study. First, the sample may not be representative of all minorities. Second, the used methods, selection process, data collection, screening and age range differed among the studies. The adherence rate was also measured at different intervals. Finally, a number of the studies included were conducted in the USA, where screening may require payment, which may not be comparable to other health services.

Evidence was found that BC screening adherence among women that belong to minority groups depends on several factors, such as sociodemographic (high income, educational level and age); personal (fear, distrust of health professionals or healthcare system, lack of knowledge and pain or discomfort); ethical, cultural and religious (religious beliefs, role of men, family and community) and external (access to healthcare, sex of the physician and efforts to bring healthcare facilities closer to women). For lowering the level of distrust and discomfort, it may be useful to assign a female physician in certain cases, considering that women may feel more comfortable with healthcare professionals of the same sex $(62,63)$. The lack of knowledge may be addressed by distributing flyers and organizing informative sessions on BC screening. This may also help to reduce womens' fear of screening, cancer detection and its consequences. It may also be valuable to establish a mobile screening program (e.g., in the form of a van), in order to deal with distrust in the healthcare system and other potential logistic barriers. The pain associated with MAM is inevitable to a certain extent, but training technicians to be aware and support women through the procedure may help minimize discomfort. It would be beneficial to consider the different backgrounds of the women that seek screening. Including husbands and partners in clinical consultations, with the patient's consent, may be a method for increasing adherence. Finally, taking into consideration that having a regular primary care provider promote screening adherence, health policies related to $\mathrm{BC}$ prevention should aim to prioritize primary healthcare.

\section{Acknowledgements}

Not applicable. 


\section{Funding}

The present study was developed under the scope of project NORTE-01-0145-FEDER- 000013, supported by the Northern Portugal Regional Operational Programme (NORTE 2020) under the Portugal Partnership Agreement, through the European Regional Development Fund (FEDER), and by National funds, through the Foundation for Science and Technology (FCT)-project UIDB/50026/2020 and UIDP/50026/2020.

\section{Availability of data and materials}

All data generated or analyzed during the present study are included in this published article.

\section{Author's contributions}

CSF, JR and SM are accountable for the integrity of this work, in particular its design, literature search, data collection and interpretation, quality assessment and manuscript preparation. FR contributed to the systematic review assessment and interpretation. ALF contributed to the conception and design and critical revision of the manuscript for important intellectual content. All the authors have read and approved the final manuscript.

\section{Ethics approval and consent to participate}

Not applicable.

\section{Patient consent for publication}

Not applicable.

\section{Competing interests}

The authors declare that they have no competing interests.

\section{References}

1. World Health Organization: WHOIBreast cancer. https://www. who.int/cancer/prevention/diagnosis-screening/breast-cancer/en/. Accessed March 22, 2020.

2. Morrell S, Taylor R, Roder D and Dobson A: Mammography screening and breast cancer mortality in Australia: An aggregate cohort study. J Med Screen 19: 26-34, 2012.

3. Nelson HD, Fu R, Cantor A, Pappas M, Daeges M and Humphrey L: Effectiveness of breast cancer screening: Systematic review and meta-analysis to update the 2009 U.S. Preventive services task force recommendation. Ann Intern Med 164: 244-255, 2016.

4. Roder D, Houssami N, Farshid G, Gill G, Luke C, Downey P, Beckmann K, Iosifidis P, Grieve L and Williamson L: Population screening and intensity of screening are associated with reduced breast cancer mortality: Evidence of efficacy of mammography screening in Australia. Breast Cancer Res Treat 108: 409-416, 2008

5. Morrell S, Taylor R, Roder D, Robson B, Gregory M and Craig K: Mammography service screening and breast cancer mortality in New Zealand: A National Cohort Study 1999-2011. Br J Cancer 116: 828-839, 2017.

6. Niell BL, Freer PE, Weinfurtner RJ, Arleo EK and Drukteinis JS: Screening for breast cancer. Radiol Clin North Am 55: 1145-1162, 2017.

7. Coleman C: Early detection and screening for breast cancer. Semin Oncol Nurs 33: 141-155, 2017.
8. Moss SM, Nyström L, Jonsson H, Paci E, Lynge E, Njor S and Broeders M; Euroscreen Working Group: The impact of mammographic screening on breast cancer mortality in Europe: A review of trend studies. J Med Screen 19 (Suppl 1): S26-S32, 2012.

9. Van Schoor G, Moss SM, Otten JD, Donders R, Paap E, den Heeten GJ, Holland R, Broeders MJ and Verbeek AL: Increasingly strong reduction in breast cancer mortality due to screening. Br J Cancer 104: 910-914, 2011.

10. Puliti D and Zappa M: Breast cancer screening: Are we seeing the benefit? BMC Med 10: 106, 2012.

11. Veitch D, Goossens R, Owen H, Veitch J, Molenbroek J and Bochner M: Evaluation of conventional training in Clinical Breast Examination (CBE). Work 62: 647-656, 2019.

12. Greenwald ZR, Fregnani JH, Longatto-Filho A, Watanabe A, Mattos JSC, Vazquez FL and Franco EL: The performance of mobile screening units in a breast cancer screening program in Brazil. Cancer Causes Control 29: 233-241, 2018.

13. Lopes LV, Miguel F, Freitas H, Tavares A, Pangui S, Castro C, Lacerda GF, Longatto-Filho A, Weiderpass E and Santos LL: Stage at presentation of breast cancer in Luanda, Angola-a retrospective study. BMC Health Serv Res 15: 471, 2015.

14. Talley CH, Yang L and Williams KP: Breast cancer screening paved with good intentions: Application of the information-motivation-behavioral skills model to racial/ethnic minority women. J Immigr Minor Health 19: 1362-1371, 2017.

15. MauadEC,Nicolau SM, Moreira LF,Haikel RL,Longatto-Filho A and Baracat EC: Adherence to cervical and breast cancer programs is crucial to improving screening performance. Rural Remote Health 9: 1241, 2009.

16. MauadEC,Silvay TB,HaikelRL,BauabS and Longatto-Filhoy A: Is community intervention in breast cancer screening in Brazil feasible? J Med Screen 18: 51, 2011.

17. Miller BC, Sarma EA, Sun Y, Messina CR and Moyer A: Psychosocial predictors of mammography history among Chinese American women without a recent mammogram. Ethn Health 25: 862-873, 2020.

18. Adu PA, Ukah UV and Palmer SD: Association between recency of immigration and mammography uptake: Results from a Canadian National Survey. J Immigr Minor Heal 19: 228-235, 2017.

19. De Andrade Souza CI, Araújo DS, Teles DA, Carvalho SG, Cavalcante KW, Rabelo WL, Alves CN and Fonseca AJ: Factors related to non-adherence to mammography in a city of the Brazilian Amazonian area: A population-based study. Rev Assoc Med Bras (1992) 63: 35-42, 2017.

20. Guo Y, Cheng TC and Lee HY: Factors associated with adherence to preventive breast cancer screenings among middle-aged African American women. Soc Work Public Health 34: 646-656, 2019.

21. Vahabi M, Lofters A, Kim E, Wong JP, Ellison L, Graves E and Glazier RH: Breast cancer screening utilization among women from Muslim majority countries in Ontario, Canada. Prev Med 105: 176-183, 2017.

22. Zorogastua K, Sriphanlop P, Reich A, Aly S, Cisse A and Jandorf L: Breast and cervical cancer screening among US and non US born African American Muslim Women in New York City. AIMS PUBLIC Health 4: 78-93, 2017.

23. Farzaneh E, Heydari H, Shekarchi AA and Kamran A: Breast and cervical cancer-screening uptake among females in Ardabil, northwest Iran: A community-based study. Onco Targets Ther 10: 985-992, 2017.

24. Pilkington L, Haigh MM, Durey A, Katzenellenbogen JM and Thompson SC: Perspectives of Aboriginal women on participation in mammographic screening: A step towards improving services. BMC Public Health 17: 697, 2017.

25. Lee EE, Nandy K, Szalacha L, Park H, Oh KM, Lee J and Menon U: Korean American women and mammogram uptake. J Immigr Minor Heal 18: 179-186, 2016.

26. Freund A, Cohen M and Azaiza F: Factors associated with routine screening for the early detection of breast cancer in cultural-ethnic and faith-based communities. Ethn Health 24: 527-543, 2019.

27. Hong HC, Ferrans CE, Park C, Lee H, Quinn L and Collins EG: Effects of Perceived Discrimination and Trust on Breast Cancer Screening among Korean American Women. Womens Health Issues 28: 188-196, 2018.

28. Molina Y, Plascak JJ, Patrick DL, Bishop S, Coronado GD and Beresford SAA: Neighborhood predictors of mammography barriers among US-based latinas. J Racial Ethn Heal Disparities 4: 233-242, 2017. 
29. Shaw T, Ishak D, Lie D, Menon S, Courtney E, Li ST and Ngeow J: The influence of Malay cultural beliefs on breast cancer screening and genetic testing: A focus group study. Psychooncology 27: 2855-2861, 2018.

30. Wildes KA, Nápoles-Springer A, Pérez-Stable E, Talavera G and Rios E: Physician gender differences in general and cancer-specific prevention attitudes and practices. J Cancer Educ 24: 85-93, 2009

31. Lee HY, Lee MH, Jang YJ and Lee DK: Breast cancer screening disparity among Korean American immigrant women in midwest. Asian Pac J Cancer Prev 18: 2663-2667, 2017.

32. Cohen EL, Wilson BR, Vanderpool RC and Collins T: Identifying sociocultural barriers to mammography adherence among Appalachian Kentucky Women. Health Commun 31: 72-82, 2016.

33. O'Hara J, McPhee C, Dodson S, Cooper A, Wildey C, Hawkins M, Fulton A, Pridmore V, Cuevas V, Scanlon M, et al: Barriers to breast cancer screening among diverse cultural groups in Melbourne, Australia. Int J Environ Res Public Health 15: 1677, 2018.

34. Ma J, Jemal A, Fedewa SA, Islami F, Lichtenfeld JL, Wender RC, Cullen KJ and Brawley OW: The American Cancer Society 2035 challenge goal on cancer mortality reduction. CA Cancer J Clin 69: 351-362, 2019.

35. Brouwers MC, De Vito C, Bahirathan L, Carol A, Carroll JC, Cotterchio M, Dobbins M, Lent B, Levitt C, Lewis N, et al: What implementation interventions increase cancer screening rates? a systematic review. Implement Sci 6: 111, 2011.

36. Yeoh KG, Chew L and Wang SC: Cancer screening in Singapore, with particular reference to breast, cervical and colorectal cancer screening. J Med Screen 13 (Suppl 1): S14-S19, 2006.

37. Australian Institute of Health and Welfare: Breast Screen Australia Monitoring Report 2006-2007 and 2007-2008. Canberra, 2010. AIHW, Canberra, Cancer series no. 55. Cat. no. CAN 51, 2010.

38. Israel Cancer Association. The Israel Cancer AssociationColorectal Cancer. http://en.cancer.org.il/template_e/ default.aspx?PageId=7747. Accessed March 25, 2020.

39. Azevedo e Silva G, Bustamante-Teixeira MT, Aquino EML, Tomazelli JG and dos-Santos-Silva I: Acesso à detecção precoce do câncer de mama no sistema Único de saúde: Uma análise a partir dos dados do sistema de informacões em saúde. Cad Saude Publica 30: 1537-1550, 2014 (In Portuguese).

40. Moser K, Patnick J and Beral V: Inequalities in reported use of breast and cervical screening in Great Britain: Analysis of cross sectional survey data. BMJ 338: b2025, 2009.

41. Nuche-Berenguer B and Sakellariou D: Socioeconomic determinants of cancer screening utilisation in Latin America: A systematic review. PLoS One 14: e0225667, 2019.

42. Davis TC, Arnold C, Berkel HJ, Nandy I, Jackson RH and Glass J: Knowledge and attitude on screening mammography among low-literate, low- income women. Cancer 78: 1912-1920, 1996.

43. Davis TC, Williams MV, Marin E, Parker RM and Glass J: Health Literacy and Cancer Communication. CA Cancer J Clin 52: 134-149, 2002.

44. Consedine NS, Magai C, Krivoshekova YS, Ryzewicz L and Neugut AI: Fear, anxiety, worry, and breast cancer screening behavior: A critical review. Cancer Epidemiol Biomarkers Prev 13: 501-510, 2004.

45. Azami-Aghdash S, Ghojazadeh M, Sheyklo SG, Daemi A, Kolahdouzan K, Mohseni $M$ and Moosavi A: Breast cancer screening barriers from the womans perspective: A meta-synthesis. Asian Pacific J Cancer Prev 16: 3463-3471, 2015

46. Katapodi MC, Pierce PF and Facione NC: Distrust, predisposition to use health services and breast cancer screening: Results from a multicultural community-based survey. Int J Nurs Stud 47: 975-983, 2010.
47. Mouslim MC, Johnson RM and Dean LT: Healthcare system distrust and the breast cancer continuum of care. Breast Cancer Res Treat 180: 33-44, 2020.

48. Keemers-Gels ME, Groenendijk RP, van den Heuvel JH, Boetes C, Peer PG and Wobbes TH: Pain experienced by women attending breast cancer screening. Breast Cancer Res Treat 60: 235-240, 2000

49. Elewonibi B and BeLue R: The influence of socio-cultural factors on breast cancer screening behaviors in Lagos, Nigeria. Ethn Heal 24: 544-559, 2019.

50. O'Reilly D, Kinnear H, Rosato M, Mairs A and Hall C: Uptake of breast screening is influenced by current religion and religion of upbringing. J Relig Health 52: 1168-1176, 2013.

51. Fox SA, Pitkin K, Paul C, Carson S and Duan N: Breast cancer screening adherence: Does church attendance matter? Health Educ Behav 25: 742-758, 1998.

52. McEwan J, Underwood C and Corbex M: Injustice! that is the cause: A qualitative study of the social, economic, and structural determinants of late diagnosis and treatment of breast cancer in Egypt. Cancer Nurs 37: 468-475, 2014.

53. Lee SY: Cultural factors associated with breast and cervical cancer screening in Korean American Women in the US: An integrative literature review. Asian Nurs Res (Korean Soc Nurs Sci) 9: 81-90, 2015

54. Kawar LN: Barriers to breast cancer screening participation among Jordanian and Palestinian American women. Eur J Oncol Nurs 17: 88-94, 2013.

55. Glazier RH, Klein-Geltink J, Kopp A and Sibley LM: Capitation and enhanced fee-for-service models for primary care reform: A population-based evaluation. CMAJ 180: E72-E81, 2009.

56. Todd L, Harvey E and Hoffman-Goetz L: Predicting breast and colon cancer screening among English-as-a-second- language older Chinese immigrant women to Canada. J Cancer Educ 26: 161-169, 2011

57. Alexandraki I and Mooradian AD: Barriers related to mammography use for breast cancer screening among minority women. J Natl Med Assoc 102: 206-218, 2010.

58. Gierisch JM, O'Neill SC, Rimer BK, DeFrank JT, Bowling JM and Skinner CS: Factors associated with annual-interval mammography for women in their 40s. Cancer Epidemiol 33: 72-78, 2009.

59. Baron RC, Melillo S, Rimer BK, Coates RJ, Kerner J, Habarta N, Chattopadhyay S, Sabatino SA, Elder R and Leeks KJ; Task Force on Community Preventive Services: Intervention to increase recommendation and delivery of screening for breast, cervical, and colorectal cancers by healthcare providers. A systematic review of provider reminders. Am J Prev Med 38: 110-117, 2010.

60. Lurie N, Margolis KL, McGovern PG, Mink PJ and Slater JS: Why do patients of female physicians have higher rates of breast and cervical cancer screening? J Gen Intern Med 12: 34-43, 1997.

61. Perez LG, Elder JP, Haughton J, Martinez ME and Arredondo EM: Socio-demographic moderators of associations between psychological factors and Latinas' breast cancer screening behaviors. J Immigrant and Minority Health 20: 823-830, 2018.

62. Smalls BL, Aroh A, McQuerry K, Adegboyega A, Schoenberg N and Hatcher J: Social support and breast cancer screening in rural Appalachia. Psychooncology 27: 2281-2288, 2018.

63. 63. Valdovinos C, Penedo FJ, Isasi CR, Jung M, Kaplan RC, Giacinto RE, Gonzalez P, Malcarne VL, Perreira K, Salgado H et al: Cancer Causes Control 27:27-37, 2016.

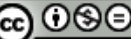

This work is licensed under a Creative Commons Attribution-NonCommercial-NoDerivatives 4.0 International (CC BY-NC-ND 4.0) License. 